\title{
Product Portfolio Decision-making Method Based on Multiple Bottlenecks
}

\author{
Lipeng Wang ${ }^{1, *}$ Chunqi $\mathrm{Li}^{1}$ \\ ${ }^{1}$ Jiangsu University of Science and Technology, Zhenjiang, Jiangsu 212003, China \\ *Corresponding author. Email: 1031761774@qq.com
}

\begin{abstract}
Determining the appropriate product mix solution is one of the important production system decisions for manufacturing companies. Based on the traditional method of identifying bottlenecks in the theory of constraints, this paper proposes a heuristic method that considers all constraints simultaneously and assigns weights to all constraints in five steps to address the infeasibility of the traditional theory of constraints in product mix decisions under multiple resource constraints. The paper also illustrates the feasibility, simplicity and ease of use of the new method through a simulation example.
\end{abstract}

Keywords: Bottleneck identification, Product mix, TOC (theory of constraints), LP (linear programming), Heuristic method.

\section{INTRODUCTION}

Determining the appropriate product mix solution is one of the important production system decisions for manufacturing companies. At present, the existing and mature product portfolio decision methods mainly include theory of constraints (TOC) and linear programming (LP) methods. Since the product portfolio decision is related to the efficiency of the enterprise, the advantages and disadvantages of the product portfolio decision methods have been concerned and debated for a long time by the academic community.

Finch D [1] and Qiu M [2] discussed the similarity between TOC method and linear programming method in product portfolio decisionmaking from theoretical and practical aspects respectively, and thought that TOC method was simpler and easier to use. Mabin V [3] discussed the complementarity of the two methods, and cited examples to illustrate. However, Balakrishnan $\mathbf{J}$ et al. [4] demonstrated the infeasibility of TOC method in product portfolio decision-making under multi-constraint conditions, and thought that linear programming method was the best method. Since the traditional TOC algorithm can only solve the single bottleneck problem, it cannot provide the optimal solution or approximate optimal solution for the multi-bottleneck resource problem. In order to solve the defects of traditional TOC in solving multi-bottleneck resource problems, scholars can only improve the traditional TOC algorithm. Improvement is mainly divided into two ways; The first is to improve TOC as an independent algorithm. Fredendall et al. [5] put forward RTOC algorithm, which has been tested and has the same result as ILP in most cases. Then Aryanezhad [6] and others tested RTOC, and found that RTOC sometimes got non-optimal solution, and optimized RTOC. De Souza et al. [7] discussed the controversial issue of comparing TOC with the optimization method of product portfolio decision, and put forward a heuristic method to obtain feasible solutions from the perspective of TOC. The results are compared with those of integer linear programming. Tanhaei et al. [8] developed a heuristic algorithm suitable for two bottleneck resources. Ajay Gupta [9] and others have improved some shortcomings in TOCh, and put forward the improved TOCh1. By comparing with the results of integer linear programming model, it is proved that this model gives satisfactory results. In addition to the research and application of TOC independent algorithm, scholars also put forward a comprehensive algorithm combining TOC with LP and intelligent algorithm, which provides a better idea for solving large-scale problems. In the research of TOC synthesis algorithm, combining 
with LP is the most common in the early stage. For example, Luebbe and Finch [1] combine ILP with TOC, and get better results than TOCh algorithm, but the processing time is longer. Recently, scholars prefer the combination of TOC and intelligent algorithm. Samouei et al. [10] of TOC comprehensive algorithm comprehensively applies FRTOC and double-layer fuzzy mathematical model to solve the assembly line balancing problem (ALBP).

However, it is not difficult to see that these improved methods either only consider the main constraints or ignore other sub-constraints. The production process of enterprises is dynamic, and the main constraints will become sub-constraints, while the sub-constraints will rise to the main constraints; or it needs to be sorted repeatedly, which makes the decision-making process more complicated. On the basis of bottleneck definition in traditional constraint theory, aiming at the situation that there are two constraint resources or multiple constraint resources in the system, this paper attempts to further improve the combination decision of products in constraint theory with a new heuristic method, which does not need the complex operation of linear programming method or repeated sequencing. The example simulation shows that the improved TOC method is simple and easy to use.

\section{METHOD OVERVIEW}

In the traditional constraint theory, when combining products, only the primary constraint resources are considered, but the secondary constraint resources are not considered. The production process is a dynamic process and the resources are interrelated, which makes the bottleneck resources shift, thus obtaining the suboptimal result, even the infeasible result. Balakrishnan $\mathbf{J}$ et al. [11] has already proved it through an example. The method given in this paper is aimed at this problem, considering all constraints and giving weights to all constraints, so as to avoid the infeasibility of planning caused by bottleneck transfer.

The improved method is divided into five steps to illustrate:

- List the load capacity table of all resources, in which the load refers to the sum of the requirements of processing all products for a certain resource capacity in a certain period of time;
- Consider all overloaded resources as constraints $C \boldsymbol{O}_{n}(n=1,2 \cdots \cdot n)$, establish constraint domain: $R=\left\{C O_{1}, \mathrm{CO}_{2}, \cdots \cdots \mathrm{CO}_{q}\right\}, 2 \leq q \leq n$;

- Calculate the proportion of each constraint resource to the total constraint resource: $W_{\mathrm{n}}=C O_{n} / \sum_{\mathrm{n}=1}^{\mathrm{q}} \mathrm{CO}{ }_{n}$; the time spent by the ith product on constraining resource $\mathrm{Q}$

is: $t_{i, C O_{q}}$; the unit benefit of the constrained resource $\mathrm{q}$ of the ith product is $r_{i}=\frac{T P_{i}}{t_{i, C O_{q}}}$

; and then multiplied by the proportion of the constraint resource to the whole constraint resource: $P_{\mathrm{i}, \mathrm{q}}=W_{\mathrm{q}} \bullet r_{i}=\frac{T P_{i}}{t_{i, C O_{q}}}$

- Will each product under different constraint resources $P_{\mathrm{i}}$ summation: $\boldsymbol{J}_{i}=\sum_{n=1}^{m} \boldsymbol{P}_{\mathrm{i}}$ of $\boldsymbol{J}_{i}$, the larger the value of $\boldsymbol{J}_{i}$, the more priority is given to scheduling (if $\boldsymbol{J}_{i}$ tends to infinity, the product is finally produced.

- Use the domain search method to determine whether to increase the total output. Alternative products are products that cannot meet the market demand and are close to the products, and only need to make local fine adjustments.

The product mix problem can also be solved by linear programming. The objective function and constraints are both linear functions of independent variables. The simplex method is the most commonly used method to solve the linear programming problem. However, in the process of solving the simplex method, a known basic feasible solution is taken as the premise, and the next basic feasible solution is determined on this basis. Therefore, in the process of solving simplex method, determining the initial basic feasible solution is the key to solving linear programming. In addition, according to the geometric meaning of linear programming, the number of effective constraints of linear programming determines the number of basic feasible solutions of linear programming. When the enterprise faces many 
constraints and its output is relatively large, it is obviously difficult for the enterprise to determine a feasible scheme from an infinite number of feasible schemes, which must conform to the nature of the basic feasible solution for optimization. However, the method adopted in this paper is simple and practical, which can avoid the problems when using linear programming.

\section{EXAMPLE SIMULATION AND RESULTS}

Godfrey $\mathrm{C}$ used examples to show that TOC can't solve the multi-bottleneck constraint, and now cited his counterexamples to verify the feasibility of the new method in this paper. Enterprises need to produce 5 kinds of products and 6 kinds of resources. The specific parameters are shown in "Table 1":

Table 1. Products and related data

\begin{tabular}{|c|c|c|c|c|c|c|c|c|c|c|}
\hline \multirow{2}{*}{$\begin{array}{l}\text { Product } \\
\text { category }\end{array}$} & \multicolumn{6}{|c|}{ Types of resources } & \multirow{2}{*}{$\begin{array}{l}\text { Market } \\
\text { demand }\end{array}$} & \multirow{2}{*}{$\begin{array}{l}\text { Retail } \\
\text { price }\end{array}$} & \multirow{2}{*}{$\begin{array}{c}\text { Prices of raw and semifinished } \\
\text { materials }\end{array}$} & \multirow{2}{*}{$\begin{array}{c}\text { TP } \\
\text { value }\end{array}$} \\
\hline & $\mathrm{P1}$ & P2 & P3 & P4 & P5 & P6 & & & & \\
\hline $\mathrm{A}$ & 2.5 & 9.5 & 6.5 & 12.0 & 4.0 & 30.0 & 20 & 30 & 10 & 20 \\
\hline B & 5.5 & 3.5 & 1.5 & 16.0 & 1.0 & 10.0 & 30 & 50 & 42 & 8 \\
\hline $\mathrm{C}$ & 3.5 & 8.5 & 9.5 & 25.0 & 2.0 & 9.0 & 40 & 50 & 25 & 25 \\
\hline $\mathrm{D}$ & 2.0 & 8.0 & 10.0 & 30.0 & 1.0 & 10.0 & 30 & 40 & 25 & 15 \\
\hline $\mathrm{E}$ & 10.0 & 20.0 & 15.0 & 0.0 & 10.0 & 2.0 & 60 & 20 & 15 & 5 \\
\hline total load & 1015 & 2075 & 1755 & 2620 & 820 & 1680 & & & & \\
\hline Capacity load & 2400 & 1825 & 2400 & 2400 & 2400 & 2400 & & & & \\
\hline Overload load & - & 250 & - & 220 & - & - & & & & \\
\hline
\end{tabular}

The above products are now classified using the method in Section 2, and the process is as follows.:

Table 2. Resource load table

\begin{tabular}{|c|c|c|c|c|c|c|c|c|}
\hline \multirow{2}{*}{$\begin{array}{l}\text { Product } \\
\text { category }\end{array}$} & \multicolumn{6}{|c|}{ Types of resources } & \multirow{2}{*}{$\begin{array}{l}\text { Market } \\
\text { demand }\end{array}$} & \multirow{2}{*}{$\begin{array}{c}\text { TP } \\
\text { value }\end{array}$} \\
\hline & $\mathrm{P} 1$ & P2 & P3 & P4 & P5 & P6 & & \\
\hline $\mathrm{A}$ & 2.5 & 9.5 & 6.5 & 12.0 & 4.0 & 30.0 & 20 & 20 \\
\hline B & 5.5 & 3.5 & 1.5 & 16.0 & 1.0 & 10.0 & 30 & 8 \\
\hline $\mathrm{C}$ & 3.5 & 8.5 & 9.5 & 25.0 & 2.0 & 9.0 & 40 & 25 \\
\hline D & 2.0 & 8.0 & 10.0 & 30.0 & 1.0 & 10.0 & 30 & 15 \\
\hline $\mathrm{E}$ & 10.0 & 20.0 & 15.0 & 0.0 & 10.0 & 2.0 & 60 & 5 \\
\hline Overload load & - & 250 & - & 220 & - & - & & \\
\hline
\end{tabular}

- List the load capacity table of each resource, as shown in "Table 2 ";

- Constraint resources are p2 and p4, $\mathrm{CO} 1=\mathrm{P} 2, \quad \mathrm{CO} 2=\mathrm{P} 4, \quad$ Constraint domainR $\{\mathrm{CO} 1, \mathrm{CO} 2\}$;
- Weight: $W_{2}=220 /(250+220) \approx 0.47$; $P_{1,1}$ of product $\mathrm{A}$ in constraint $C O_{1}$ is $20 / 9.5 * 0.53=1.12, P_{1,2}$ of product 
$\mathrm{A}$ in constraint $\mathrm{CO}_{2}$ is $20 / 12 * 0.47=0.78$, The rest of the products are analogized;

- Find

out: $J_{1}=1.9, J_{2}=1.4, J_{3}=2.0, J_{4}=1.2, J_{5}=\infty$ Therefore, the priority of products is C,A,B,D,E;
- according to the priority, the final products are $40 \mathrm{C}, 20 \mathrm{~A}, 30 \mathrm{~B}, 22 \mathrm{D}, 50 \mathrm{E}$. because $\mathrm{d}$ cannot meet the market demand, the alternative products are $\mathrm{B}$ and $\mathrm{E}$.

The replacement process and results are shown in "Table 3"

Table 3. Product substitution process and results

\begin{tabular}{|c|c|c|c|c|c|c|c|c|c|c|}
\hline & D & B & E & & $\begin{array}{l}\mathrm{P} 1 \\
\end{array}$ & P2 & P3 & P4 & P5 & P6 \\
\hline 1 & +2 & -3 & 0 & 6 & 1513.5 & 8.5 & 859.5 & 8 & 1689 & 830 \\
\hline 2 & +4 & -7 & 0 & 4 & 1531.5 & 6.5 & 845.5 & 12 & 1691 & 850 \\
\hline 3 & +6 & -10 & 0 & 10 & 1544 & 1 & 830 & 0 & 1692 & 860 \\
\hline 5 & +10 & -18 & -1 & 1 & 1590 & 17 & 817 & 8 & 1706 & 902 \\
\hline 6 & +12 & -24 & 0 & -12 & 1609 & 2 & 791 & 44 & 1700 & 940 \\
\hline
\end{tabular}

The final scheduling result is $20 \mathrm{~A}, 20 \mathrm{~B}, 40 \mathrm{C}$, 28D, 50E.

$\mathrm{TP}=20 * 20+20 * 8+40 * 25+28 * 15+$

$50 * 5=2230$

This is consistent with the result obtained by Godfrey C [11] using linear programming method. This method is still feasible when applied to the cases in related literatures [12-25].

\section{CONCLUSION}

Based on the bottleneck determination method in constraint theory, this paper improves the product portfolio decision-making method in constraint theory by considering all constraints and giving weights to them. Compared with Godfrey C.'s method, this method not only avoids the professional knowledge and complicated calculation required by linear programming method, but also adheres to the method of bottleneck determination in constraint theory, and does not need to repeat production scheduling, which simplifies the steps of product combination, is convenient for managers to use, and can achieve the same results. TOC is obviously different from LP. As a process, TOC provides a perfect framework for improving throughput, and has a wide impact on product portfolio determination, scheduling, inventory buffer placement, inspection placement and so on. Its target is beyond the target range of LP. It provides an intuitive and effective way to promote the continuous improvement of organizational functions.

\section{AUTHORS' CONTRIBUTIONS}

Lipeng Wang is responsible for conceiving and writing. Chunqi Li sorted out the data used in this paper.

\section{REFERENCES}

[1] Luebbe, R.L. and B.J. Finch, Theory of constraints and linear programming: a comparison. International Journal of Production Research, 1992. 30(6): p. 14711478.

[2] Qiu, M., L. Fredendall and Z. Zhu, TOC or LP? [production control]. Manufacturing Engineer, 2002. 81(4): p. 190-195.

[3] Mabin, V.J. and J. Gibson, Synergies from spreadsheet LP used with the theory of constraints - a case study. Journal of the Operational Research Society, 1998. 49(9): p. 918-927.

[4] Jaydeep, et al., Theory of constraints and linear programming: a re-examination. International Journal of Production Research, 2000. 38(6): p. 1459-1463.

[5] Fredendall, L.D. and B. Lea, Improving the product mix heuristic in the theory of constraints. International Journal of 
Production Research, 1997. 35(6): p. 15351544.

[6] Professor, M. and A. Komijan, An improved algorithm for optimising product mix under the Theory of Constraints. International Journal of Production Research, 2004. 42(6): p. 4221-4233.

[7] De Souza, F.B., et al., When less is better: Insights from the product mix dilemma from the Theory of Constraints perspective. International Journal of Production Research, 2013. 51(19): p. 5839-5852.

[8] Tanhaei, F. and N. Nahavandi, Algorithm for solving product mix problem in two-constraint resources environment. The International Journal of Advanced Manufacturing Technology, 2013. 64(5): p. 1161-1167.

[9] Gupta, A., Modified Theory of Constraints Heuristics(MTOCh1) Keeping Complete Shipment as Constraint. Universal journal of management, 2016. 4(12): p. 670-677.

[10] Samouei, P., et al., Bottleneck easing-based assignment of work and product mixture determination: fuzzy assembly line balancing approach. Applied Mathematical Modelling, 2016. 40(7): p. 4323-4340.

[11] Onwubolu, G., Tabu search-based algorithm for the TOC product mix decision. International Journal of Production Research, 2001. 39(5): p. 2065-2076.

[12] Aryanezhad, M.B. and A.R. Komijan, An improved algorithm for optimizing product mix under the theory of constraints. International Journal of Production Research, 2004. 42(20): p. 4221-4233.

[13] Zhuang, Z. and S. Chang, Deciding product mix based on time-driven activity-based costing by mixed integer programming. Journal of intelligent manufacturing, 2015. 28(4): p. 959-974.

[14] Balakrishnan, J. and C.H. Cheng, Discussion: Theory of constraints and linear programming: A re-examination. International Journal of Production Research, 2000. 38(6): p. 14591463.

[15] Verma, R., Management science, theory of constraints/optimized production technology and local optimization. Omega, 1997. 25(2): p. 189-200.
[16] Gupta, A., Modified Theory of Constraints Heuristics(MTOCh1) Keeping Complete Shipment as Constraint. Universal Journal of Management, 2016. 4(12): p. 670-677.

[17] Komijan, A.R. and S.J. Sadjadi, Optimizing product mix in a multi-bottleneck environment using group decision-making approach. international conference on computational science and its applications, 2005. 38(6): p. 388-396.

[18] Coman, A. and B. Ronen, Production outsourcing: A linear programming model for the Theory-Of-Constraints. International journal of production research, 2010. 38(7): p. 1631-1639.

[19] Bhattacharya, A. and P. Vasant, Soft-sensing of level of satisfaction in TOC product-mix decision heuristic using robust fuzzy-LP. European Journal of Operational Research, 2007. 177(1): p. 55-70.

[20] Tanhaie, F. and N. Nahavandi, Solving product mix problem in multiple constraints environment using goal programming. Industrial Engineering and Management, 2017. 4(1): p. 1-12.

[21] Onwubolu, G.C., Tabu search-based algorithm for the TOC product mix decision. International Journal of Production Research, 2001. 39(10): p. 2065-2076

[22] Ray, A., B. Sarkar and S.K. Sanyal, The TOCBased Algorithm for Solving Multiple Constraint Resources. IEEE Transactions on Engineering Management, 2010. 57(2): p. 301-309.

[23] Balakrishnan, JaydeepCheng and C. Hung, Theory of constraints and linear programming: a reexamination, in q, Q, $\mathrm{Q}^{\wedge}$ Editors. 2000, Taylor \& Francis: q. p. 1459-1463.

[24] Hilmola, O. and M. Gupta, Throughput accounting and performance of a manufacturing company under stochastic demand and scrap rates. Expert Systems With Applications, 2015. 42(22): p. 8423-8431.

[25] Okutmuş, E., A. Kahveci and J. Kartašova, Using theory of constraints for reaching optimal product mix: An application in the furniture sector. Intellectual Economics, 2015. 9(2): p. 138-149. 